Sheridan College

SOURCE: Sheridan Institutional Repository

$7-6-2020$

\title{
Tailor Made, Skylarking, and Making in the Humanities
}

Dale Tracy

Royal Military College of Canada

Follow this and additional works at: https://source.sheridancollege.ca/fhass_creative_humanities

\section{SOURCE Citation}

Tracy, Dale, "Tailor Made, Skylarking, and Making in the Humanities" (2020). Creative Humanities Special Issues. 1.

https://source.sheridancollege.ca/fhass_creative_humanities/1

\section{(c) (1) $9 \odot$}

This work is licensed under a Creative Commons Attribution-Noncommercial-No Derivative Works 4.0 License. This Article is brought to you for free and open access by the Faculty of Humanities \& Social Sciences (FHASS) at SOURCE: Sheridan Institutional Repository. It has been accepted for inclusion in Creative Humanities Special Issues by an authorized administrator of SOURCE: Sheridan Institutional Repository. For more information, please contact source@sheridancollege.ca. 


\section{TAILOR MADE, SKYLARKING, AND MAKING IN THE HUMANITIES.}

\section{Dale Tracy}

\section{Abstract}

Reacting to the symbolic features and historical artefacts that invite institutional self-reflection at the Royal Military College (RMC), I created a performance project leading to two storytelling events. Everyday campus life at RMC already offers opportunities for cultivating a meta-perspective-a higher-order awareness - of the institution, and the storytelling events called attention to such opportunities. I argue that, likewise, art-based projects in the humanities call attention to the creativity - the making-involved in the humanities more broadly. The first storytelling event, Tailor Made (2017), comprised stories focused on the uniform as a model and the body wearing it as an actual bearing out that model. Social and cultural life is made of the difference between models and actuals, and each story engaged the ways that rules, systems, and practices meet with individuals in hurtful, inconvenient, funny or messy ways. The second event, Skylarking (2018), included stories of the institutionally condoned pranks called "skylarks" and coincidentally occurred against the backdrop of a campus-wide punishment that elicited a skylark response. This event and its context showed that marking disruption with more disruption (marking failure with punishment and marking punishment with prank) is a recursion that invites higher-order thinking about existing orders.

\section{Keywords}

Creative humanities; institutional culture; higher-level thinking; university disciplines; performance; storytelling; social and cultural life; order and disruption; metonymy; Royal Military College

\section{Author Affiliation}

Dale Tracy PhD, Assistant Professor, Department of English, Culture, and Communication, Royal Military College of Canada (Dale.Tracy@rmc.ca)

Tracy, Dale. "Tailor Made, Skylarking, and Making in the Humanities." Forthcoming from University of Toronto Quarterly (online ahead of print). First published online 6 July 2020 (https://source.sheridancollege.ca/fhass_creative_ humanities/1/). 


\title{
TAILOR MADE, SKYLARKING, AND MAKING IN THE HUMANITIES.
}

\author{
Dale Tracy
}

I started thinking about institutional culture when I was hired as a sessional at the Royal Military College of Canada in 2014-I continue there as a nonpermanent assistant professor in the Department of English, Culture, and Communication-because RMC is an institution that is hyper-aware of its cultures.' The daily routine exists through and with the symbolic features, historical artefacts, and cultural messaging that make up this campus such that the experience is a meta-experience: there is, as part of everyday life, the higher-level consideration of what it means to be at RMC. ${ }^{2}$ Add to this that the institution is small and physically isolated on a peninsula, making it possible and frequent that the entire college-faculty, staff, and studentsshares experiences, and it becomes difficult not to have a sense of the RMC community in everyday life. These reflections led me to create a performance project at RMC: I wanted a forum for performing the meta-awareness that is already part of the everyday. I created a storytelling event that has had two iterations, one focused on uniforms Tailor Made (2017) and the other on pranks Skylarking (2018).

In creating the first storytelling event, I used three cultural texts-a book of paper dolls, a book of poetry, and a book of creative nonfictionas models for the new cultural text. The event, focused on uniforms, was itself about models. Uniforms are cultural texts that actualize concepts-for instance, the concepts of uniformity and teamwork, and, in this context, the concepts of leadership and nation. Uniforms also operate as models for actual bodies to live in and up to. Any actual expression of a concept can serve as a model for a new expression. The uniform is a piece of attire and a model of order; when people wear the uniform, they become new models of that order. Through this contiguous chain of actual texts and new models, meaning moves through metonymical deferral: the uniform is conceptually and physically contiguous to the person who wears it and then stands in for its concepts. ${ }^{3}$ The second event showed, through its stories of pranks, error, and failure, that the disruption between model and actual is the space for creativity. ${ }^{4}$ The event also showed that disruption marks the existing order. In this sense, disruption is a way for order to refer to itself: this meta move marks the gaps between models and actuals in which we make and re-make social and cultural life.

Tailor Made (Perfect Uniforms) 
After my idea for a performance event engaging RMC's meta qualities, the Dean of Arts agreed to fund the project. This funding brought Queen's drama professor Julie Salverson as consultant and local artist Bill Penner as director. As a first step, I solicited stories and advertised possibilities for participation through an email sent to the College Master list. Julie Salverson, visiting all first-year students at RMC in her capacity as an adjunct drama facilitator, invited further participation. At an initial sounding, we explained the idea to potential participants and asked the RMC community what they would hope to see in such a performance. Next, a devising workshop allowed interested participants to generate stories together through theatre games. Following the workshop, Bill Penner worked with participants one at a time to develop stories, asking each storyteller about what was at the heart of the story.

These meetings were important because storytellers did not necessarily perform their stories: some shared stories for other performers to learn and shape with their own experiences. This format created collaborative stories of institutional experience, fostered greater diversity in participation, and allowed participants to choose anonymity. We sought to avoid asking an individual storyteller to share a sensitive story in a structure that seems to offer witness but actually falls short, a real risk for popular theatre, as Julie Salverson explains in her article "Performing Emergency: Witnessing, Popular Theatre, and The Lie of the Literal." Salverson argues that we must be thoughtful when "soliciting autobiography" (182) for "popular theatre projects," a genre in which "some or all of the performers are members of the target communities" (181). In popular theatre, she has found that a too strong "desire to be faithful to the integrity of the storyteller" results in what she calls "the lie of the literal" in which the solicited autobiographical material is reproduced with such exactness that new forms in which storytellers and audience members can understand differently are not created (182-184). She argues that it is the "gap" between the "single, authentic story" and the story as expressed in new form that "holds the circle of knowing open and invites a current that prevents steering a straight line through the story, or arriving at a predetermined destination" (184). Salverson's observations suggest the importance of creative disruption when stories are used as models for new stories: the lie of the literal is that the original has a cohesive oneness that is best served by exact repetition.

This gap between model and actual emerged as a topic through the focus on uniforms in Tailor Made's stories. Thinking about RMC's campus Tailor Shop, which fits uniforms to individuals, the project asked, "What is it like to wear your uniform?" The free one-hour event took place in the college library, in an intimate room with plush chairs, plants, and shelves of books on the topic of leadership. After an introduction from me and the director, the event flowed from story to story, with each teller coming informally from the audience to the floor as the previous story finished. The stories were in 
French and English, and came from students, faculty, and staff, and from both academic wing and military training wing, though most stories were from and performed by students. The question about uniforms prompted stories with recurring themes that can be summed up by the difference between model and actual: breaking rules, messing up, getting caught (or not), and finding the human in the uniform. Whether reconciling their own individuality with the uniform and all it symbolizes or recognizing that individuality in military superiors, the question about uniforms generated reflection on the individual's role in the symbolic, interrelational, and prescribed structures at work at RMC as an academic and military institution.

All stories we received were included, with some being expressed in two short scenes bookmarking the other stories. These scenes synthesized the stories that were told to us again and again by various students and expressed significant aspects of campus life. The first scene, of a uniform inspection, showed a superior's duty to enforce perfection, cadets' desire to achieve it, and the deeper significance of uniform precision. The final scene moved through key points in cadets' four years at RMC in narrated tableau, from first receiving their uniforms, to the obstacle course (a rite of passage near the start of the first year), to graduation. The final story was a poem written and performed by a professor from the Department of English, Culture, and Communication who is also a major in the military and a graduate of RMC. His reflection on his career spoke to and extended the consideration many of the eleven student performers gave in their stories to how their training and learning would shape their futures. Along with the individual stories and scenes, two students performed songs from a nineteenth-century opera set at RMC. This intertextuality indicates the fact that these stories are generated on a campus with a long history; the reach of tradition in artifact, practice, and symbol is part of what it is like to wear the uniforms.

Each story engaged the ways that rules, systems, and practices meet with the human in hurtful, inconvenient, funny or messy ways. I will use one story from Tailor Made to demonstrate the way the individual (actual) meets with tradition, convention, or expectation (model). This story involved two Asian students swapping uniforms so that one could take the place of the other at uniform inspection, freeing the other to go to an event. The plan hinged on the inspector not noticing the difference between the two friends, and the story thus engaged the stereotype that "all Asians look the same" through the idea of the de-individuation of the uniform. This story involves institutional practices and rules as they intersect with individual bodies and the social codes and assumptions shaping that intersection. Like the lie of the literal, this story involves the lie that a model simply co-occurs with an actual.

What is important is not that the plan worked-the plan working doesn't prove something about the individual doing this inspection, just as the plan not working would not have verified that RMC is somehow free from a prejudice active in the wider society-but that the plan made sense. 
This student based his plan on a stereotype he trusted he could rely on to be active. He used the gap between the oppressive model (that all look the same) and the reality (that individuals are distinct and distinguishable) to meet, with creativity, an institutional demand for uniformed individuality (they are individually identifiable via the institutional identification card worn on the uniform). His subterfuge strategically collapsed the gap, playing along with the stereotype's stultifying idea that model and actual are identical.

Using the more broadly functioning model of the stereotype alongside the model of the uniform, the student disrupted institutional structures to his own advantage - not to change the stereotype but for individual benefit (helping a friend to attend an event). This was a high-risk, low-reward venture: nothing in the institution would change if the students were caught because, if caught, the stereotype would not have been active at that moment, as planned. Likewise, getting away with it means nothing changes since to get away is to keep the secret. However, telling the story in the storytelling event (a meta act) communicates the collapsed gap. Because participants didn't necessarily tell their own stories in the play, the student maintained anonymity against any potential of belated punishment: the storytelling event responds to the high-risk, low-reward venture as a low-risk, high-reward opportunity.

\section{Cultural Texts as Models and Actuals}

Creative humanities projects are meta-activities. With the OED's definitions, I am using "meta" in the sense of "dealing with second-order questions" or "higher level" thinking which, when "[p]refixed to the name of a subject or discipline [...] raises questions about the nature of the original discipline and its methods, procedures, and assumptions." RMC is meta-institutional-it fosters higher-level thinking about institutional culture and identity-and the creative humanities are meta-humanities in the same way. I am also thinking about "meta" as an adverb or adjective, meaning "self-referential," "whereby something (as a situation, person, etc.) reflects or represents the very characteristics it alludes to or depicts." I am using "recursive" to "[d\}esignat[e] a rule which can be reapplied to a form or construction that is itself partly or wholly derived by that rule." That is, to recurse is "to perform the same sequence of operations on successive results." To understand institutional structures more broadly, this essay takes the storytelling event as its model, which took RMC's institutional structures as its model. To take a self-referential, higher-order perspective on such recursivity is to notice what deferral and disruption produce.

I understand art-based projects in the humanities to show more obviously the creativity - the making - that is in the humanities more broadly. Thinking about this event and the process of its creation led me to consider not only what this project made, but what the humanities make. Humanities research works by resetting ideas in cultural texts: from the models available 
in cultural texts-like poems, musical scores, archival documents, election ads, tweets, or academic articles-, humanities scholars create new cultural texts-like classroom conversation, conference presentations, academic articles, blog posts, tweets, poems, or performances. A scholarly essay (a text about other texts) seems not to make anything: an essay seems merely derivative, not an actual in itself, like a scientific experiment or a novel more clearly is. But to write an essay that elucidates the models in cultural texts is also to make a cultural text with its own models that can in turn produce more cultural texts responding to those models. An essay is no less an actual, with its own models, than the cultural text it engages. ${ }^{5}$ It doesn't make sense to say that, for example, a poet practices culture while a literature scholar theorizes it: they both do both. I don't mean that there is no difference between a scholar and poet: both make social and cultural life, but they each do so in their chosen form and genre. My understanding of models and actuals highlights the deferral of meaning through different kinds of texts, and the disruptions of that meaning as it travels.

The texts that scholars in the humanities study teach us how to read them in part because social and cultural texts are always to some extent selfreferential: each text is its own concrete expression and also a model of that expression. Each text is a model of a logic or idea, but it is also the concrete expression of that logic; this concrete expression can, in turn, be the model of a new concrete expression. For example, in the story from Tailor Made, the student read the model of uniformity in both the uniform and the stereotype, then actualized that uniformity in a way that seemed to reproduce the model of sameness but actually produced difference as one student subbed in for the other. Similarly, humanities scholars can read institutional contexts to create new texts that are part of and respond to the institutional cultures within which we and our students learn: we can act on the systems we teach, study, and live in with the programs modelled by our subjects of study. In the gap between model and actual is room for improvisation and thus creativity.

The idea that the humanities only produce abstract knowledge not put into practice is related to the idea that all scholars in the humanities do is read cultural texts well- "texts" in the narrow sense of, say, poems or paintings -and thus only replicate texts without disruption. Jennifer Summit writes against "modern tendencies to collapse the humanities into their content" (671), arguing that "current defenders of the humanities often locate the value of their work in their objects of study-literature, the arts, philosophy-but leave untouched the scholarly practices that humanities scholars bring to them" (673-4). These scholarly practices are creative. As Alexander Hollenberg explains, "the creative text engenders further creativity by soliciting our sustained attention, complex pattern recognition, and interpretive choice-a mode of choice that prepares us for creative engagement with the world beyond the text" (49). In fact, he concludes, "Creativity is always constituted through criticality" (63). It doesn't make sense to understand our objects of study as texts that do something but our humanities work as texts that do 
nothing, that merely extract the model from the creative text to repeat it more clearly.

This separation of doing and thinking (as though thinking isn't doing) is involved in Summit's suggestion that, considering the high numbers of humanities students who become teachers, what humanities scholars study, teach, and do is learning: "Humanities majors may be drawn to education, as Mario Biagioli asserts, because 'education [is] the main 'product' the humanities has to offer," an assertion that leads Summit to "conclude that students enter the humanities not to "engage in learning about the human' (Mora), but to engage in learning about learning" (673). I disagree that education is what the humanities make, but Summit's attention to the meta-in her conclusion that humanities learning is about learning-is elucidating nevertheless. In my view, the humanities' main "product" is social and cultural life along with a higher-order perspective on the making of social and cultural life - the same thing any discipline makes. Learning to learn is necessarily learning to live and thus not separate from learning about the human-or the non-human. The gibe "those who can't do, teach" takes for granted that learning does not involve doing, assuming that learning about learning to teach about learning is a dead circle that produces nothing. But in learning to learn through social and cultural texts, society and culture is produced and practiced. The humanities make social and cultural life-with each other, students, scholars in other disciplines, and wider publics-by learning and teaching it, which is in fact doing and making it. ${ }^{6}$

This is true not only in the humanities and other disciplines but also in social and cultural life more generally. In his introduction to the first section of Creativity and Cultural Improvisation, Tim Ingold builds upon Jerome Bruner to conclude: "there can be no distinction in practice between learning culture and (re)creating culture, since the contexts of learning are the very crucibles from which the cultural process unfolds" ("Modes of Creativity in Life and Art" 51). Ingold and Elizabeth Hallam in Creativity and Cultural Improvisation, who are "talking here about the process of social life" (6), explain social life as creative and creativity as improvisation. They argue that "improvisation is the way we work, not only in the ordinary conduct of our everyday lives, but also in our studied reflections on these lives in fields of art, literature and science" (1). This improvisation demonstrates the indivisibility of thinking and doing: "because it is the way we work, the creativity of our imaginative reflections is inseparable from our performative engagements with the materials that surround us" (3). For an example that is directly relevant to a performance project, Augusto Boal's famous Theatre of the Oppressed emphatically shows what is always the case to various degrees: theatre can model real life while also being real itself: audience members, or spec-actors, come on-stage to try solutions to problems they face. This activity provides a meta-perspective not simply on social and cultural life but on the making of social and culture life. Boal argues that "the act of transforming reality, even in image, is a transformatory act, since the image of the real is real at the same time as it 
is an image" (85, emphasis in original). Like work in the creative humanities, Boal's theatre work is a form of making that makes clearer less obvious forms of making. The storytelling event at RMC made an image of institutional culture that was also itself participating in (that is, making) that culture. It was itself made from both literary texts (like poems) and institutional texts (like uniforms) showcasing the work scholars in the humanities are doing all the time with their content and in their contexts.

\section{Paper Dolls, Proxies, and Model City}

Tailor Made was inspired by RMC but also by textual models that produced for me a confluence of ideas about the relationship between models and actuals. I encountered Paper Dolls as a professor at RMC. At the same time, I was teaching Brian Blanchfield's Proxies at Queen's University and I was reading Donna Stonecipher's Model City as a scholar of poetry and poetics. Pre-existing models are the context for any new creation. As Hollenberg puts it, one must "attend to the responsibilities of the creative act within a larger socio-cultural matrix" (64). The socio-cultural matrix involves contextual elements as a creative act brings them to bear on one another in a new actual.

At RMC, Chief Librarian Sarah Toomey purchased, for the library's Special Collections, a book that tells the stories of women who served in the Unites States military. In 2013, a collaboration between the Shotwell hand paper mill in San Francisco and women serving in the military produced a book the women hand-made out of their own pulped uniforms. In her introduction, Editor Pam DeLuco stresses this interaction as important for "connecting them to the book on a deeper level" (np). Paper Dolls: stories from women who served tells these stories in part through paper dolls that can be pressed out and dressed in uniforms made of this recycled uniform paper. DeLuco writes, "I felt the interactive nature of a paper doll would allow the reader to connect to the stories more fully. Even if you choose to not cut out the doll, the potential to do so remains." The book's reception thus, in DeLuco's mind, would mirror its production: the book models its own logic by recursively operating this program of interaction. It also resets the meaning of the uniform on each page, highlighting a special article of clothing pertinent to each story with the accompanying paper doll. The book made me wonder what it was exactly that a structure of resetting interaction with uniforms offered and how I might offer it at my institution.

In an essay called "On Reset," poet and essayist Brian Blanchfield finds poetic insight watching an audition tape: the scene plays out again and again, each time with a new auditioning actor. What interests him is the tape's lack of chronological development that replicates poetry's "inclination to reset" in which any "equivalent unit sews a relationship that subtends and subverts the unidirectional" development (124). This subversion of the 
unidirectional is like Salverson's gap that prevents a straight line through a story-for Salverson, the gap is created by resetting a person's story through art. Blanchfield finds in poetry and other structures with "parallel, substitutive, paradigmatic" development (122) a theory-practice that leaves "singularity recast as multiple" (126). In Tailor Made, the stories similarly reset to answer the question of "What is it like to wear your uniform"-instead of any overall progression, the performance presented parallel stories, some of them amalgams of several originals. Blanchfield notes that the audition tape "was not meant as a whole," and experiencing it as one "makes the viewing a kind of code management, the reading a kind of writing" (123). Similarly, the stories for Tailor Made arrived distinctly one from another; they were given independently and then brought together without any effort to reconcile them to an overarching narrative. Thus, Blanchfield's idea that "authorship itself is reassigned by this structure" is relevant to Tailor Made, which opened "the call to pattern recognition"7 to the audience who might put together elements of the institution made multiple through parallel stories.

Blanchfield connects the audition tape to poetry, writing that poetry is "the arrangement of language whereby the sensations of reading are charged with the creative feeling of writing" (123-4). Poetry is one kind of model for inviting creative authorship since, in Blanchfield's words, "it teaches you how to read it" (124). ${ }^{8}$ For Blanchfield, a "recursive" poem (one that resets), as it goes about the "processing of its materials," is "something with which to think"; this "iterative processing suggests a program, one to operate" (124). Further, Blanchfield finds that each such moment of "welling confluent creativity" brought on by some poem-like occurrence brings back to him previous moments of creativity (126). Tailor Made recursively operated RMC's program as a meta-institution, much like reading a poem recursively operates the program of poetry's logic-the logic that a poem self-referentially teaches you how to read. The creativity it invites occurs through thinking in the space between the program it teaches you to read (model) and how you operate it (the actual with its possibility for new models).

Donna Stonecipher's collection of prose poems engages the logic of reset and the process of modelling. Mode/ City, inspired by Stonecipher's visits to several utopian model cities, gives 288 answers to the question, "What was it like?" Each answer begins, "It was like..." Writing what it was "like" involves the gap between sameness and similarity. That gap is the space for creativity, and it is the space the poem builds into again and again. In the story from Tailor Made, the uniform is "like" uniformity, but it has a name tag, which is "like" individuality, but this identifier is removable and (illicitly) exchangeable. For Blanchfield, when a poem teaches how to read it, "its set of likenesses and equivalences build an interiority as you pass through it" (124)-likewise institutional systems; likewise stereotypes. This interiority is the gap of selfdifference that disruption can pass through.

While Model City is about constructing cities as homes that can sustain us, its structure is also about how the future-which we must understand 
through what we know today, through our familiar models-can be built differently through the gap for creativity these models offer. Mostly, though, Model City is about the sadness of seeking the ideal, the no place of utopia. It is about models failing in the actual. The last poem in the collection, "Model City [72]" ends, "It was like thinking about model cities and about hotels, and realizing that of course no model city ever allocated space for a hotel, for why should there be any vacancy in the fully realized ideal?" (85). The model city, the poem suggests, leaves no room for visiting influences. As Salverson argues of popular theatre, the gap between the model and the actual is necessary. As Hallam and Ingold argue of creativity as the process of social life, improvisation is necessary. Visiting occurs in the messy human reality, not in utopia, and it occurs in what Salverson's essay calls "gaps" and Stonecipher's poem calls "vacancy." In a presentation at the 2017 Congress of the Humanities and Social Sciences for the panel "Protocols and Pedagogies: Indigenous Ethics in the Classroom," Warren Cariou noted the importance of visiting. Speaking of using class time for visiting without set objectives, Cariou argued that significant work is often done in this visiting. While the panel and Cariou's talk, "Visiting as Protocol," were particularly about the study of Indigenous literatures, Cariou's abstract for his talk suggests that this observation is broadly relevant (broadly relevant, that is, if continuing to recognize and respect the specific context from which the insight arose, the model that might inspire new actuals): his talk would "consider the ways that apparently non-formal kinds of interactions prove crucial to establishing the relationships that are often required for stories to be told." ${ }^{\prime \prime}$ Visiting and telling life stories are activities that make relationship. Life stories, told within and about an institution, show the gap between utopic models and actual lived life.

But making institutional space for life stories requires not only vacancy for improvisation but also recognition that forms of response are actual creations. In a commentary on Model City, Stonecipher considers her poems, with their strict stanzaic structure and repeated opening, to offer "deep structure as an aesthetic ersatz for any deep directed structure in daily life" (41). Ultimately Stonecipher thinks her poems, offering ersatz, reflect the failure of the fully realized ideal of the model city. While the collection begins with "Q:" for question and, on the next page, "What was it like?", the poems are not positioned as answers to this opening inquiry. It is only after the poems that we reach "A:" for answer and then "Berlin and elsewhere / 2010-2014." The poems' resetting answers occur outside of the structural position for the answer. For Stonecipher, the real answer is the actual places she has been-it was like Berlin and elsewhere - and the poems are only an "aesthetic ersatz" of that reality. However, her collection offers an important function that belies this thinking of it as one more failed model. Indeed, positioning the real cities - the failed models of utopia - as the answer to the question of "What was it like?" is the lie of the literal that Salverson worries about: the poems are not merely ersatz in their aesthetic following of-and 
diverging from - the cities' models. The new actual works in the gap between "like" and "is," and the lie of the literal is the lie that no such gap exists. This lie denies disruption.

Working within this gap meant being flexible with the model I had for the storytelling project. This flexibility respects the gap between model and actual in which might occur a meta-perspective of a community examining itself to benefit itself. Such flexibility also may be what differentiates, to the extent that the two can be differentiated, the event as a learning opportunity produced through community from an artistic product produced by artists: the artists here were not pursuing their own goals but responding to the community. For example, in my original conception, Tailor Made would maximize the ideas of reset and participation I found in Paper Dolls. Performers would tell their stories to small groups, directed from the circulation desk, in the library stacks, and audience members would be invited to respond with their own stories to the performer as well as to create a book jacket-the uniform of the book-depicting their experience of the event or their own uniform story. This creation would involve interaction akin to the interaction of the paper-making for DeLuco's Paper Dolls and, if linked to that book in the library's Special Collections, would clearly show the work of using cultural texts as models for new actuals.

The event was simplified for several practical reasons: most of the students were first-time performers for whom the improvisation of my initial imagined structure might be overwhelming. Additionally, the students' schedules left little time for rehearsal. To retain the participation idea, the director planned to facilitate story sharing among audience members after the performers were done, but we didn't have time to do this within the scheduled hour. While the initial vision might have led to an effective artistic product, by following what emerged in working with the participants, we made something that better suited the community. Indeed, the enthusiastic response from audience members, at the event and later, suggests that the event was well designed for the context.

Still, there is a difficulty here in the larger picture: creative projects may seek to provide an alternative or improved model of the classroom or institution. But how might a project create a new model if it must shift to meet the current actual? How might it be possible to make space for change while adhering to what the institution needs based on what it already is? How might a project respect individuals' needs in a particular context while also making spaces for discovering new needs or new approaches to existing needs? I will come to an answer to these questions by engaging the second storytelling performance at RMC.

\section{Skylarking (Marking Error)}

The first storytelling performance generated stories about failure and 
punishment-uniforms worn incorrectly and push ups demanded. The skylark event had this same central theme-taking pranks too far or failing to pull them off. A recent book about RMC, Traditions of Excellence: Royal Military College of Canada, explains skylarks this way: "a well-conceived and well-executed skylark -as these pranks by cadets are called-is a tribute to the planning skills, teamwork, and ingenuity of the perpetrators [...] Memorable skylarks at the College since 1960 are described on the Internet, and the current rules for conducting a skylark are outlined in the Royal Military College of Canada Cadet Handbook" (152). Skylarks disrupt the order, but they are also part of that order: there are codified rules to follow in executing a prank. Skylarks are themselves a tradition, and thus a pattern, even as they disrupt the flow of everyday life. These contradictions are what led me to think about the relationship between order and disorder.

This event, attending to failure and disruption, importantly coincided with real-time punishment and prank. I couldn't have known that the event would occur during an unexpected disruption unofficially dubbed "the Great Confinement." The performance took place in a week when the entire student population was confined to barracks, a punishment resulting from many individuals having been caught breaking the dress code. Students have to wear smart casual attire when off-campus and not in uniform. Apparently a general culture of breaking this rule had developed, resulting in the Great Confinement. ${ }^{10}$

In response to the punishment, a group of Civil Engineering students created a skylark. This skylark involved Brucie, a college landmark that Traditions of Excellence describes: "The bronze statue of a male officer cadet that stands beside Currie Hall overlooking the north end of the Parade Square is a gift from the RMC Club, unveiled during celebrations of the centennial of the College in November 1976" (154). The cadets built a cage of metal bars around Brucie, reflecting the confinement they were experiencing. Traditions of Excellence explains that "Brucie has been the site of numerous College pranks over the years, and the herald of many College social events. He stands immovably as the model cadet" (154). In the skylark and more generally, Brucie symbolizes the student body as the model cadet. $\mathrm{He}$ is indeed "immovably" model. Brucie as stationary model contrasts the disruptively moveable human reality - the reality that led to the immovability of confinement as the punishment pointing out the actual cadets' failure to achieve the immovable model. Attached to Brucie's free-standing cage was a sign reading: "The wrong kind of bars since March 2. We're all in this together." The bars refer to the bars of the cage in contrast to the bars students earn for their uniforms when awarded leadership positions. But the skylark highlights the expectation that cadets maintain discipline not only in leadership positions but also more broadly: from the skylark's perspective, the punishment is about the need for teamwork.

The skylark comments on the punishment for a lack of discipline with precisely the idea of the team: "We're all in this together." The confinement 


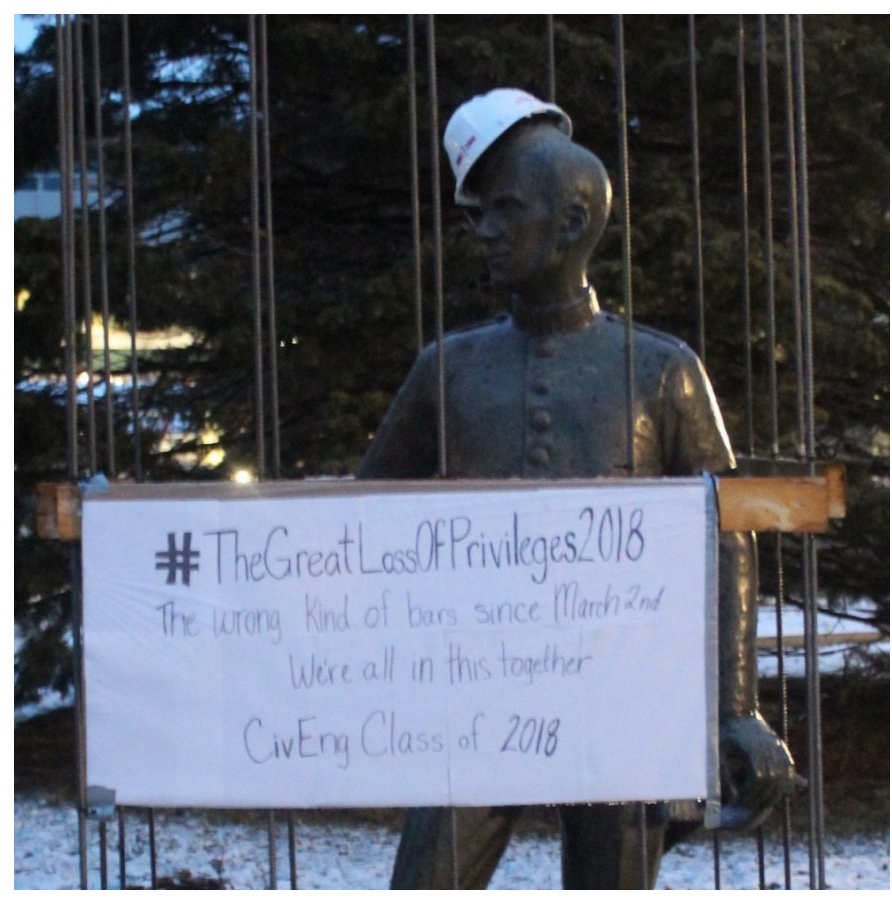

Brucie, the model cadet [photo credit: eVeritas http://everitas.rmcclub.ca/professional-development-lectures-reality/] skylark responds to the stress of punishment by disrupting the status quo in a way that precisely reinforces the desired status quo. That is, the students were punished for not acting together, and the skylark commenting on the punishment asserts togetherness as response. Disorder supports order. The students' response to the punishment does the work the punishment seeks to enforce. While the skylark's sentiment suggests as much, so does the process of the skylark: a group of cadets took initiative as leaders to produce a symbol of community for the college by working as a team. I understand this initiative to show the cadets taking on the lesson on their own terms: we may be locked in together, but we're also banding together, of our own accord. This creative work doesn't change the punishment, but it certainly changes its meaning and its implications. In some cases, breaking and rewriting the rules is possible or appropriate; in other cases, finding ways to follow the rules on one's own terms may be an important exercise of creativity." For students training to be leaders, as students at RMC are, responding to a model with reference to the demands of the context at hand is certainly an important exercise of creativity.

Institutions produce gaps they sanction—like skylarks at RMC-and also gaps they don't. The possibilities that erupt from the gap of individual distinction within perfect uniformity cannot be fully anticipated or regulated. Whether sanctioned or unsanctioned, spaces for newness are built into the systems we live in. Using these gaps requires creativity to be interpersonal and contextual, in contrast to a widespread idea that, as Sarah Brouillette describes it in Literature and the Creative Economy, for creativity "the social is a form of constraint to be transcended" (56). Making creative change within an institution means using institutional forms in new ways. Creativity reworks institutional context. For example, in the story from Tailor Made, a cadet used an expected sameness (a stereotype) to enact an identity exchange via the institution's uniform; in the Great Confinement, cadets exempting themselves from expected sameness (a dress code) elicited a shared punishment. In the first situation, creativity with institutional forms worked; in 
the second, self-exemption from institutional forms did not work. The second example is perhaps not best understood as creativity because it refused rather than reworked context, in contrast to the reaction to punishment that reworked the punishment.12

There is another way that students at RMC perform a relation to their errors through punishment: wearing $4 \mathrm{~S}$ and $\mathrm{Gs}$. Uniforms for different occasions are numbered, and "Gs" means gaiters, a covering over the boots and the bottom of the pants. The punishment is a disruption of typical dress, of the typical way of moving around the campus: to disrupt through breaking a rule is to be made a walking disruption. The punishment is to move through the world as an errer: as one who errs. Erring means to stray from the accepted course: to err is to walk awry. ${ }^{13}$ In my reading, 4s

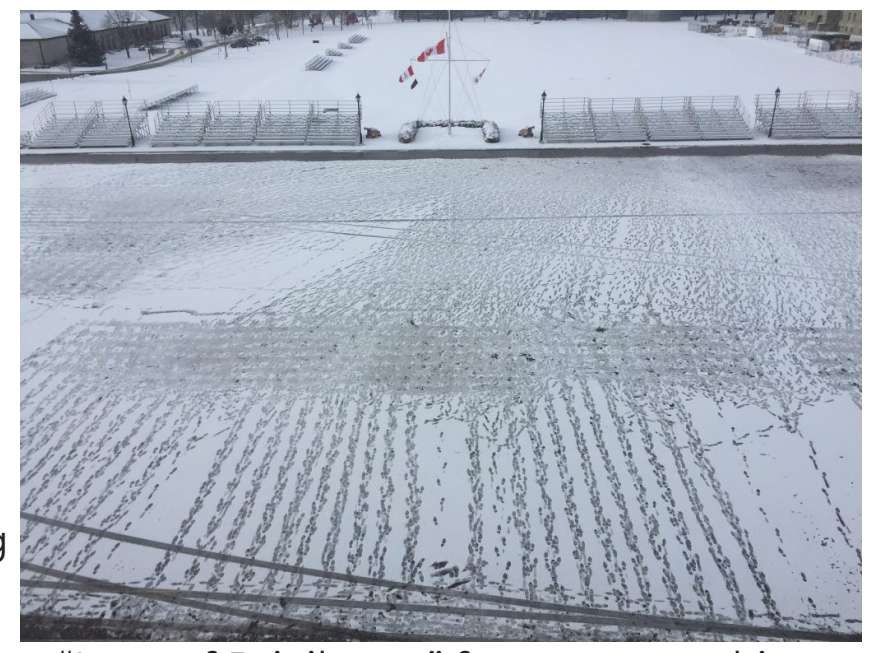

"Loss of Privileges" form-up: marking error [photo credit: eVeritas http://everitas.rmcclub.ca/professional-development-lectures-reality/] and Gs say, "you have erred, you have walked awry, so now walk as error but walk straight. Perform the error by moving through the world as the sign of it." Punishment is itself a disruption that responds to an earlier disruption. The punishment for disruption is to mark that disruption. This is a recursive move that suggests a higher-order (meta) commentary on error.

Though the uniform as punishment certainly suggests an understanding of error as negative, errors are ways of accessing our realities . Error as a mode of self-access returns me to Blanchfield's Proxies, a collection of essays devoted, in a sense, to error. Blanchfield writes each single subject essay with reference to history, philosophy, cultural theory, and literary texts wholly from memory, without checking for correctness. Having determined that he would make "[s] usceptibility to error...a hazard inherent" to his collection of essays, Blanchfield notes that this decision to work with "a total suppression to other authoritative sources" led him to be "immediately drawn to a second constraint": "to stay with the subject until it gives onto an area of personal uneasiness, a site of vulnerability, and keep unpacking from there" (vii). For Blanchfield, the decision to court error and to disrupt the cultural and scholarly authority of his essays immediately became a decision to court and learn from his own vulnerability. Moving into error is what allows him to understand his own path through the authorities outside of himself that he remembers but does not check in with. Thus, this is not an exercise that scorns context or seeks to move against it; rather, it is an exercise in understanding one's relationship to pre-existing authorities, particularly as that understanding opens up further understanding of the self. 
In Proxies, Blanchfield notes that a proxy is a stand-in-the speaker of these partly autobiographical essays is a literary stand-in for the author who wrote them. But he adds, "In sciences I think proxy additionally expresses a kind of concession to imprecision, a failure. It's the word for a subject you choose to study to produce data that can approximate the data you'd get from the actual, desired subject, if it were not prohibitively hard to apprehend" (viii). Perfection is the actual, desired subject of the uniform, but it is prohibitively hard to apprehend: the perfectly worn uniform is always a proxy for the perfection it stands in for. Wearing 45 and $G$ s is a sign of error (it marks the failure to follow the rules) but it is also a concession to failure. The uniform must be worn perfectly and kept in perfect condition: it is a sign of non-error, of mastery, control, and obedience. 4s and Gs are a standin for error, for the messy human reality, but this uniform also must be worn perfectly. As a sign of error, this uniform is a concession to failure within the system of order. At the same time as the uniform is a stand-in for the error, it is a correction to that error. The student who suppresses authority by erring against it finds the personal uneasiness (whether cognitively and emotionally or only physically in heavy gaiters) of becoming, in these clothes, a stand-in for error and a stand-in for the concession of error. While I can't speak to the self-knowledge students have when wearing the uniform, there does seem to be a knowledge of the system articulated in the disciplinary uniform and that knowledge is this: there cannot be mistakes and there must be mistakes.

To mark an error on the student's body (on the student body) means that the fact of disruption is visible as a disruption. The mark of error is a mark of recursivity and deferment. Perfection is the model reapplied to each form, but actual perfection is necessarily deferred. The uniform stands in for perfection metonymically. In metonymy, things are associated through spatial or conceptual contiguity, not through similarity or sameness: the cadets, as humans, are not like perfection, but they associate themselves with perfect uniformity through the uniform as a sign of order. A metonymical relationship shows the gap between one thing and another: to mark error with the uniform is to mark the gap between model and actual. The marked error activates the gap and makes it visible, reminding everyone that the person who erred participates in a system in which error is unavoidable, however much perfection is essential.

Creativity-as-disruption works in the gap between model and actual. The activities I've discussed work by strategically concealing and revealing the gaps in which creativity is possible. The skylark marked error with a cage made contiguous to Brucie, the model immovable cadet, shifting the sense of static perfection to immovability as punishment. The assertion that "we're all in this together" suggests that the student body is in this cage with Brucie, contiguous to his immovable perfection and thus a proxy for it. In Tailor Made, the identity exchange precisely did not mark the error through its use of a stereotype that doesn't allow for difference: an illicit substitution mobilized the stereotype that only white people are differentiable by exploiting the 
perfect sameness of the uniform.

If $\mathrm{RMC}$ is the meta-institution it seems to me to be, it is not surprising that so many students found it desirable to tell tales of their failures in both storytelling events. The storytelling event was an opportunity to come together over what is already made clear in everyday life at RMC: failure and error are essential aspects of aiming for perfection. The event offered space to analyze RMC's cultures and practices, but skylarks (chosen) and 45 and Gs (forced) had already marked in the social space what individuals shared in the event.

Skylarking students perform disorder unseen. They leave the mark of their disorder on the campus in a way that disorders daily life. The sign of the performance (the skylark) does what the performance (making the skylark) did. A student breaks a rule and, later, wears 45 and Gs, a disruption of daily dress, to mark the disruption. The sign of the error does what the error did. The prank and punishment are both meta-discourses of the act of disruption. They both say, "there is disruption here." What I'm wondering is, what could be such meta-discourses in academic institutions without skylarks and uniforms? ${ }^{14}$ Is there a way of marking error that says, "of course there is error and failure here"? Meta-discourse facilitates questions about how institutional agents receive student creation and how institutional contexts implicitly or explicitly invite students to think about mistakes in their academic work. By assigning punishment, the training wing at RMC makes errors salient. By grading assignments, the academic wing at RMC makes errors salient. $4 \mathrm{~S}$ and Gs are a uniform that reminds students that they should have stuck to the rules the perfect uniform signifies. Do professors' marks on the page suggest to students that they should have stuck to the rules the perfect assignment signifies?

Not necessarily. I think that RMC's institutional context makes clear that to be a leader means having the capacity to respond to models in ways appropriate to the contexts in which one finds oneself. Skylarks embody this space between model and decision, whereas $4 \mathrm{~S}$ and $\mathrm{Gs}$ embody the mistake of flouting rules, of ignoring models. RMC implicitly provides two different models for understanding marked divergence from a model.

The two approaches that skylarks and $4 \mathrm{~s}$ and $\mathrm{Gs}$ model exist more generally for educators. The approach I'm understanding here through $4 \mathrm{~s}$ and Gs involves a focus on the difference between model and new work in terms of deficit from an ideal, which puts emphasis on the model over the process of creation. As a professor, if I'm looking for the difference between the model and a student's work, I might be seeing the deficit only. If I look from this perspective, I might treat student work as though it has the type of mistake that flouts the rules. What needs to be punished? Bad behaviour. What needs to be marked up? Bad work. In contrast, skylarks model a way to make models one's own by creatively departing from them with a nuanced and appropriate relation to context. Professors wishing to approach student work for its creative engagement with models might do so in terms of the 
errors of an imperfect skylark, not in terms of the rule-breaking signalled by 45 and Gs. The trick is, I think, to find compelling ways to model this distinction within one's particular institution.

I'm talking about approaching creativity within the existing orders that institutions create. At RMC, skylarks and marked errors reinforce the existing orders. At other institutions, too, we use grading to mark error to uphold existing orders. Error has penalty (a low grade), and it is our job (as professors, instructors, or teaching assistants) to administer it. A low grade has its own consequences in terms of passing courses, earning degrees, gaining admittance to graduate programs, and obtaining employment. Thus, part of our job is to keep order: in this example, to order our students in terms of their successes and failures and thereby, to some extent, their later social movements. This isn't to say that the discipline and punishment in academic institutions is the same as that in cadet military training; rather, it is to say that in both cases disruption is marked to uphold the current order.

Whether intended to participate in or overturn entrenched systems, creativity does make the most of the gaps available; this is my answer to my question about what it means to have made a storytelling event that fits the context already in place. Disruption appropriate to the context makes the most of the gap between model (the context) and actual (the new creation) by closely observing the gaps available in the context and producing a higher order perspective on them through new actuals. This is not to say that this is the only tactic for disruption, but it is to say that the storytelling event used the tactic that is most often at work in the humanities-as in other disciplines, but apparent in the humanities only if it is recognized that the humanities make something. We make social and cultural texts that closely respond to our models. We disrupt social and cultural texts with our readings of them by working with the gaps they provide, and by offering a higher-order awareness of those gaps.

Marking disruption with disruption is a recursion that invites higherorder awareness of existing orders. While error and failure tend to be understood as an individual's difference from the proper order, social and cultural life is actually made of the difference between models and actuals: it is the creative improvisation of relational life. Error, failure, misalignment, or disruption are thus forms of creativity that create social and cultural life, whether deliberate or not. ${ }^{15}$ From this perspective, the challenge for scholars in the humanities is to show students and colleagues their errors and failures not only comprehended within the orders that exist (grading or peer review, both based in conventions and expectations) but also within the disorder we must create when we make social and cultural life, which is what we are always making, in error and out. Because examining disruption through an art-based project in the humanities gave me insight into what the humanities make, I suggest that the creative humanities offer a meta-discourse on the (already meta) processes of making disruption. Making much of the difference between a model and a new actual is in contrast to seeking to 
actualize models of utopia, the "fully realized ideal," which, Stonecipher tells us, would have no "vacancy."

Online Ahead of Print | University of Toronto Quarterly | Special Issue on The Creative Humanities https://source.sheridancollege.ca/fhass_creative_humanities/1/ 


\section{Endnotes}

1 The Royal Military College is a university at which Officer and Naval Cadets obtain four-year undergraduate degrees and military commissions. Training to be officers at the same time as completing degree requirements, the cadets must succeed in four pillars: academics, military, physical fitness, and bilingualism. Though RMC is both military and academic, I am a civilian scholar. This essay thus provides insight into teaching in the humanities and teaching in an academic institution, not into the military. I'm reflecting on the context of my teaching and I'm thinking about what my reflections might mean for thinking about humanities classrooms and institutional cultures more broadly.

2 As Traditions of Excellence explains, "The RMC grounds are adorned with myriad memorials: historic aircraft, armoured fighting vehicles, artillery pieces, field engineer bridging and weaponry, including a naval turret. As well, there are statues, plaques, the Wall of Honour, memorial trees, walkways, pillars, chairs, gates, and other memorials" (80). The book as a whole reinforces my point: the book's very existence is proof of metainstitutionalism.

3 Metonymy is a trope in which something stands in for something else closely related to it; it also refers to the combinatorial axis of language in Roman Jakobson's definition. Lacan follows this definition when he understands metonymy in terms of how "one signifier constantly refers to another in a perpetual deferral of meaning" (Evans 114). We can likewise think here of Derrida's "différance" to notice that a text's differing and deferring from itself is the potential allowing any text to become a model for a new text. There are thus two forms of gap: one, between items in a contiguous chain (the combinatorial axis of language and, in my argument, of texts) and two, within texts (the difference and deferral endemic to any apparent whole).

$4 \quad$ Moving in and through the gap between model and actual entails necessarily partaking of what already exists, and we all do this in every moment of our living - l'm not talking about the more circumscribed set of actions often imagined as wholly new and called "innovation." Thus, I do not use "disruption" to mean disconnecting from tradition, as it has been used to mean in neoliberal contexts-for example, in Clayton M. Christensen's The Innovator's Dilemma and The Innovative University.

5 I do not mean that all texts should be treated as art, an idea critiqued in Imre Szeman's "Neoliberal's Dressed in Black: or, the Traffic in Creativity." Szeman writes against the "rhetorical and conceptual gesture of transforming human activity (or at least its potential) as such into art-and an idea of art taken not from sociology but from fantasies about its ideal relationship 
to something called creativity" (35). "The effect," Szeman explains, of this generalized idea of art and amorphous sense of creativity "is to render mute the critical capacities and political function of art and culture, even as it becomes coterminous with human life activity as such" (35). Instead, my argument pertains to the relationships of deferral that involve texts of all sorts. As models become new actuals through this deferral, attention to the sorts of texts involved is necessary for understanding the relationships produced.

$6 \quad$ We are not making, say, Nigerian culture when we read a text written by a Nigerian author about Nigeria in a Canadian classroom. We are making social and cultural life in the context we are reading in. But the social and cultural life engaged in and modelled by the text becomes part of how we make our social and cultural life where and as we are (with these plural pronouns containing a great deal of difference as they intersect with that "where" and "as").

7 I quote Hollenberg using this same phrase, which he takes from Brian Boyd's "Arts, Humanities, Sciences, Uses." Boyd cites neuroscientist Gerald Edelman's comment about the workings of the human brain: "brains operate prima facie not by logic but rather by pattern recognition" (577). Boyd's point is that because art lacks immediate use it is able to have deeper use as it offers a "high and repeated dosage of intensely focused attention to humanly relevant pattern" (578). When critical texts treat these patterns in art as models, they produce new models themselves, even as they comment, with higher-order thinking, about the patterns they produce.

8 Poetry is a good example of the way cultural texts function as models and actuals. The logic of reset nicely suggests the same. I don't mean to suggest that poetry and resetting are the superior form and logic for the humanities. Rather, poetry that models the logic of reset is a clear example of what I'm talking about when I talk about the meta and the recursive.

9 In his article "Life-Telling: Indigenous Oral Autobiography and the Performance of Relation," Cariou writes, "What I call "life-telling" is something that we all do, no matter where we come from or where we intend to go" (314). However, K. Tsianina Lomawaima argues in her article for the same special issue (Indigenous Conversations about Biography) that "[t]he Indigenous biographical project/process is as simple-and complex-as looking for relationships; which, so far as I can tell, is not quite the bullseye in the target of mainstream biography, where relationships seem not of the same scale, character, or stakes as the relationships at play in Indigenous biography" (248-249). I engage with Indigenous perspectives on making good relationship in the blog post "What We Make in the Humanities," which offers an early version of my ideas here and was invited by ACCUTE for its blog English Matters after my conference presentation about Tailor Made. Another

Online Ahead of Print | University of Toronto Quarterly | Special Issue on The Creative Humanities https://source.sheridancollege.ca/fhass_creative_humanities/1/ 
place for insight into the theory-practice of making social and cultural life, and also touched on in the blog post, is critical making. For example, Patrick Jagoda writes that in critical making there is a "blurring of the established distinction between theory and practice," noting that " $t$ this binary has been particularly entrenched in literary criticism" and "central to Western thought" (358).

10 In what follows, I am not presenting RMC's motivations behind the punishment nor speculating about the punishment's validity or success in terms of cadet discipline. My expertise extends only to how these events fit into my understanding of my teaching context.

11 I mean for this broader point to be practical, not quietist. In many cases, changing the rules may be absolutely necessary from an ethical perspective; yet, finding ways to live within currently unacceptable frameworks is also a practical necessity, one that can involve multiple strategies, including but not limited to breaking rules.

12 I don't mean that refusal can't be an important political move, but that institutional refusal is a different move than is institutional creativity.

13 That errs in senses of the verb: "†wandering, roaming (obsolete); deviating from the right or intended course, missing the mark; that is in error, or commits errors in opinion or conduct" ("Erring," OED).

14 Both skylarks and 45 and $G$ s are part of a military institutional context. They have specific meaning gained metonymically through that larger social field. The way they make error social is particular to that context; other institutions would need different metonyms, appropriate to themselves, and these are what I'm interested in. The sheer possibility of disciplinary attire indicates the specificity of the relation between individual bodies and the institution in the military context. (My thanks to Giorelle Diokno, audience member at the Canadian Association of Theatre Research's annual convention where I presented some of these ideas, for reminding me of the utility of metonymy here.)

15 None of this is meant to valorize errors but rather to normalize their unavoidability. Similarly, none of this is meant to valorize existing orders (I don't relish my role in marking error) nor to suggest that current ways of doing are inevitable or most desirable. Rather, I'm considering the gaps in what exists and the creative making going on there. 


\section{Works Cited}

Blanchfield, Brian. Proxies: Essays Near Knowing. Nightboat, 2016.

Boal, Augusto. The Aesthetics of the Oppressed. Translated by Adrian Jackson. Routledge, 2006.

Boyd, Brian. "Arts, Humanities, Sciences, Uses." New Literary History, vol. 44, no. 4, 2013, pp. 575-594. JSTOR. 10.1353/nlh.2013.0041. Accessed 18 Feb 2019. Brouillette, Sarah. Literature and the Creative Economy. Standford UP, 2014.

Cariou, Warren. "Visiting as Protocol" in "Protocols and Pedagogies:

Indigenous Ethics in the Classroom." Congress of the Humanities and Social Sciences, 28 May 2017. Abstract posted on English Matters, 9 Mar 2017, accute. $\mathrm{ca} / 2017 / 03 / 09 /$ protocols-and-pedagogies-indigenous-ethics-in-the-classroom/. Accessed 6 Jun 2017.

---."Life-Telling: Indigenous Oral Autobiography and the Performance of Relation." Biography, vol. 39, no. 3, 2016, pp. 314-327, doi.org/10.1353/ bio.2016.0041. Accessed 6 Jun 2017.

DeLuco, Pam. Paper Dolls: stories from women who served. Shotwell Paper Mill, 2013.

"Erring." OED Online. Accessed 4 Jun 2020.

Evans, Dylan. An Introductory Dictionary of Lacanian Psychoanalysis. Routledge, 1996.

Hallam, Elizabeth and Tim Ingold, editors. "Creativity and Cultural Improvisation: An Introduction." Creativity and Cultural Improvisation. Berg, 2007, pp.1-24.

Hollenberg, Alexander. "Challenging Creativity: A Critical Pedagogy of Narrative Interpretation." English Studies in Canada, vol. 43, no. 1, 2017, pp. 4566.

Ingold, Tim. "Modes of Creativity in Life and Art: Introduction." Creativity and Cultural Improvisation. Edited by Elizabeth Hallam and Ingold, Berg, 2007, 4554.

Jagoda, Patrick. "Critique and Critical Making." PMLA, vol. 132, no. 2, 2017, pp. 356-363.

Lomawaima, K. Tsianina. "A Principle of Relativity through Indigenous Biography." Biography, vol. 39, no. 3, 2016, pp. 314-327, doi.org/10.1353/ 
bio.2016.0041. Accessed 6 Jun 2017.

"Meta." OED Online. Accessed 4 Jun 2018.

Paziuk, Larry, project manager. Traditions of Excellence: Royal Military College of Canada. Edited by Irwin Streight, Sarah Toomey, Mary Cameron and Chris Miner (photo editor/principle photographer). Royal Military College of Canada, 2016.

"Recurse." OED Online. Accessed 4 Jun 2018.

"Recursive." OED Online. Accessed 4 Jun 2018.

Salverson, Julie. "Performing Emergency: Witnessing, Popular Theatre, and The Lie of the Literal." Theatre Topics, vol. 6, no. 2, 1996, pp. 181-191. Project Muse, muse.jhu.edu/article/35168. Accessed 26 Jul. 2016.

Skylarking. Directed by Bill Penner, Royal Military College of Canada, 2017. Stonecipher, Donna. Model City. Shearsman, 2015.

---. "Model City with a Critical Introduction on Prose Poetry and the City." Dissertation, University of Georgia, 2011. purl.galileo.usg.edu/uga_etd/ stonecipher_donna_201105_phd. Accessed 26 Jul. 2016.

Summit, Jennifer. "Renaissance Humanism and the Future of the Humanities." Literature Compass, vol. 9, no. 10, 2012, pp. 665-678, 10.1111/j.17414113.2012.00921.x. Accessed 25 Jul 2017.

Szeman, Imre. "Neoliberal's Dressed in Black: or, the Traffic in Creativity." English Studies in Canada, vol. 36, no. 1, 2010, pp. 15-36.

Tailor Made. Directed by Bill Penner, Royal Military College of Canada, 2017.

Tracy, Dale. "What We Make in the Humanities." English Matters, 29 Aug 2017, accute.ca/2017/08/29/dale-tracy-rmc-what-we-make-in-the-humanities/. Accessed 5 Jun 2018. 